\title{
Application of an $O$-Linked Glycosylation System in Yersinia enterocolitica Serotype O:9 to Generate a New Candidate Vaccine against Brucella abortus
}

\author{
Jing Huang ${ }^{\dagger}$, Chao Pan ${ }^{\dagger}$, Peng Sun, Erling Feng, Jun Wu, Li Zhu * ${ }^{(D)}$ and Hengliang Wang * \\ State Key Laboratory of Pathogen and Biosecurity, Beijing Institute of Biotechnology, 20 Dongdajie Street, \\ Fengtai, Beijing 100071, China; jinghuangpaper0203@163.com (J.H.); panchaosunny@163.com (C.P.); \\ sunpeng990718@163.com (P.S.); fengel@sohu.com (E.F.); junwu1969@163.com (J.W.) \\ * Correspondence: wanghl@bmi.ac.cn (H.W.); jewly54@126.com (L.Z.); Tel.: +86-10-63802181 (H.W.) \\ + These authors contributed equally to this work.
}

Received: 24 February 2020; Accepted: 19 March 2020; Published: 20 March 2020

\begin{abstract}
Brucellosis is a major zoonotic public health threat worldwide, causing veterinary morbidity and major economic losses in endemic regions. However, no efficacious brucellosis vaccine is yet available, and live attenuated vaccines commonly used in animals can cause human infection. $\mathrm{N}$ - and $\mathrm{O}$-linked glycosylation systems have been successfully developed and exploited for the production of successful bioconjugate vaccines. Here, we applied an $O$-linked glycosylation system to a low-pathogenicity bacterium, Yersinia enterocolitica serotype O:9 (Y. enterocolitica O:9), which has repeating units of O-antigen polysaccharide (OPS) identical to that of Brucella abortus (B. abortus), to develop a bioconjugate vaccine against Brucella. The glycoprotein we produced was recognized by both anti-B. abortus and anti-Y. enterocolitica O:9 monoclonal antibodies. Three doses of bioconjugate vaccine-elicited $B$. abortus OPS-specific serum IgG in mice, significantly reducing bacterial loads in the spleen following infection with the B. abortus hypovirulent smooth strain A19. This candidate vaccine mitigated $B$. abortus infection and prevented severe tissue damage, thereby protecting against lethal challenge with A19. Overall, the results indicated that the bioconjugate vaccine elicited a strong immune response and provided significant protection against brucellosis. The described vaccine preparation strategy is safe and avoids large-scale culture of the highly pathogenic B. abortus.
\end{abstract}

Keywords: Yersinia enterocolitica serotype O:9; Brucella abortus; O-linked glycosylation; bioconjugate vaccine; brucellosis

\section{Introduction}

Brucellosis is one of the most common zoonotic diseases worldwide and it has re-emerged in several countries in recent years [1]. More than 500,000 new cases of brucellosis are reported each year [2], and millions of livestock are either infected or at risk [3]. Incidence is likely significantly underestimated because of the wide distribution, mild clinical features, and frequent misdiagnosis of the disease [4]. Brucellosis is mainly caused by Brucella spp., which are Gram-negative and facultative intracellular $\alpha$-proteobacteria. Brucella melitensis, Brucella abortus, and Brucella suis are the most virulent of these species. Humans are mainly infected by direct contact with infected animals or through the consumption of non-pasteurized dairy products [5]. In humans, infection is chronic and patients gradually lose their ability to work. Although rarely fatal, human brucellosis is very serious [6,7], requiring long-term antibiotic treatment and often causing permanent sequelae [8].

At present, animal vaccines against Brucella are live attenuated vaccines, and these have played an important role in controlling the spread of brucellosis [9]. However, the efficacy of these vaccines is not ideal [10] — they can cause abortions and infertility in animals, disease in humans [11,12], and 
do not confer sufficient protection [9,13,14]. For example, S19 and RB51 are two commonly used live attenuated vaccines against $B$. abortus but despite being attenuated, these vaccines can result in infections in humans and are also secreted into the milk of immunized animals [15]. RB51 is resistant to rifampicin and penicillin, making clinical treatment challenging. In addition, evaluation of the live attenuated vaccine often requires the use of virulent smooth strains in biosafety level-3 laboratories, which is not conducive to extensive research. However, there are currently no better alternatives $[9,16,17]$ and, most importantly, there is still no human brucellosis vaccine available $[4,18]$. Efforts toward further attenuation have ultimately failed $[19,20]$.

The surface polysaccharide of Gram-negative bacteria is an immunodominant antigen, and studies have shown that antibodies against B. abortus O-antigen polysaccharide (OPS) elicited by active immunization can provide a protective effect in mice [2,21]. Similarly, Jacques et al. showed that immunization of mice with B. melitensis OPS covalently linked to BSA induces protective effects [22]. These results demonstrate that antibodies against OPS are associated with anti-Brucella effects and may play an important role in host defense [23]. Therefore, the development of a brucellosis vaccine based on OPS is a promising avenue for the prevention of brucellosis.

Polysaccharide conjugate vaccines produced via the covalent conjugation of bacterial surface polysaccharides to proteins have been very successful, with several efficacious vaccines of this type having been produced using chemical methods and approved for market release [24]. However, this method involves multiple steps and is time-consuming, making it costly and difficult to apply in developing countries and poorer areas [25]. With the discovery of bacterial glycosylation systems and the development of synthetic biology, the preparation of conjugate vaccines using biosynthetic methods has become a hot topic $[26,27]$. It has been demonstrated that an $N$-linked glycosyltransferase, PglB, from Campylobacter jejuni can be expressed in Escherichia coli and catalyze the glycosylation of its natural substrate, AcrA [28]. Subsequently, various vaccines based on the PglB glycosylation system were developed, including vaccines against Shigella dysenteriae type I [29], Francisella tularensis [30], Staphylococcus aureus [31], and Streptococcus pneumoniae [32,33]. Several of these vaccines have entered clinical trials [25]. Researchers also identified another O-linked glycosyltransferase, PglL, from Neisseria meningitidis that has broader substrate specificity and, therefore, transfers a greater variety of polysaccharides for bioconjugate vaccine preparation [34]. One such example is the transfer of galactose at the reducing end of the OPS of Salmonella enterica serovar Paratyphi A [35]. In recent years, a novel PgIS (an O-linked oligosaccharyltransferase from Acinetobacter spp.) glycosylation system was developed for pneumonia capsule polysaccharide glycosylation [36].

Yersinia enterocolitica can be divided into 60 serotypes and six biological types. A highly pathogenic strain is $Y$. enterocolitica bioserotype $1 \mathrm{~B} / \mathrm{O}: 8$, and $Y$. enterocolitica $\mathrm{O}: 9$ is a Class II biosafety hazard organism [22,37]. Y. enterocolitica O:9 has an identical structure of repeat units in OPS to that of B. abortus [37]. Therefore, a bioconjugate vaccine against B. abortus could be produced in Y. enterocolitica O:9 without biosafety risk. Previously, glycosylated AcrA was obtained in Y. enterocolitica O:9 with the $N$-linked glycosylation system, although this glycoprotein generated an IgG antibody response but failed to exert a protective effect in mice [22].

In this study, we produced a bioconjugate vaccine against $B$. abortus by introducing an $O$-linked glycosylation system into $Y$. enterocolitica $\mathrm{O}: 9$, which avoided the cloning of large fragments of bacterial polysaccharide-encoding genes and the low efficiency of exogenous expression. Besides its biosafety advantages, Y. enterocolitica O:9 is easy to manipulate and culture, while B. abortus grows slowly and requires specific culture conditions. Through the catalysis of PglL, the OPS from Y. enterocolitica O:9 could be conjugated to the recombinant cholera toxin B subunit (rCTB). A series of animal experiments showed that our bioconjugate vaccine was safe and could induce effective immune responses in mice, providing a potential candidate vaccine for the prevention and control of brucellosis. Moreover, the evaluation of our vaccine made use of the hypovirulent smooth strain of B. abortus, which is less pathogenic than the virulent smooth strain. 


\section{Materials and Methods}

\subsection{Bacterial Strains, Growth Conditions, and Plasmids}

Y. enterocolitica O:9 strain 52212 (YeO9_52212) and the B. abortus hypovirulent smooth strain A19 were provided by the Institute for Communicable Disease Control and Prevention, Chinese Centre for Disease Control and Prevention, Beijing, China. YeO9_52212 was cultured in Brain Heart Infusion (BHI) medium at $25^{\circ} \mathrm{C}$. To induce plasmid expression in the bacteria, cells were cultured to an optical density at $600 \mathrm{~nm}$ of $0.6-0.8$, followed by the addition of isopropyl- $\beta$-D-thiogalactopyranoside (IPTG) to a final concentration of $1 \mathrm{mM}$ and further culture of the cells at $25^{\circ} \mathrm{C}$ for $14 \mathrm{~h}$. B. abortus strain A19 was cultured in Tryptic Soy Broth (TSB) medium at $37^{\circ} \mathrm{C}$. Solid media contained $1.5 \%$ agar. Plasmids (pET-pgIL-CTB4573H and pET-CTB4573H) were constructed based on our previous work [38]. Kanamycin $(50 \mu \mathrm{g} / \mathrm{mL})$ was used for plasmid selection as required.

\subsection{Western Blotting}

IPTG-induced cells $(1 \mathrm{~mL})$ were collected by centrifugation and then resuspended in $100 \mu \mathrm{L}$ of $\mathrm{ddH}_{2} \mathrm{O}$. The whole-cell or purified samples were mixed with 1:1 (v/v) $1 \times$ Loading Buffer $(100 \mathrm{mM}$ Tris- $\mathrm{HCl}, \mathrm{pH} 6.8,3.2 \%$ (w/v) SDS, 0.04\% (w/v) bromophenol blue, 16\% (v/v) glycerol, and $40 \mathrm{mM}$ DL-dithiothreitol). The samples were placed in a boiling water bath for $10 \mathrm{~min}$ and then cooled to room temperature. After centrifugation at $10,000 \times g$ for $10 \mathrm{~min}, 10 \mu \mathrm{L}$ of each sample was subjected to SDS-PAGE and western blotting using the methods described in our previous work [38]. Horseradish peroxidase-conjugated $6 \times$ His-tag antibody (Abmart, Shanghai, China) was used to detect the His-tagged proteins. A B. abortus monoclonal antibody (Thermo Fisher Scientific, Waltham, MA, USA) was diluted 1:100 and used to detect polysaccharides of B. abortus in the glycoproteins. A Y. enterocolitica O:9 monoclonal antibody (Fitzgerald, Acton, MA, USA) was diluted 1:200 and used to detect $Y$. enterocolitica $\mathrm{O}: 9$ polysaccharide in the glycoproteins.

\subsection{Glycoprotein Purification}

IPTG-induced cells (7 L) were collected by centrifugation and then resuspended in $300 \mathrm{~mL}$ of Buffer A1 (20 mM Tris- $\mathrm{HCl}, \mathrm{pH} 7.5,10 \mathrm{mM}$ imidazole, and $0.5 \mathrm{M} \mathrm{NaCl}$ ), after which the cells were disrupted by ultrasound for $2 \mathrm{~h}$. The supernatant of the cell lysate was harvested by centrifugation at $10,000 \times g$ for $20 \mathrm{~min}$ and then loaded onto a nickel affinity column (cOmplete His-Tag Purification Resin, Roche, penzberg, Germany) that had been pre-equilibrated with five column volumes of Buffer A1. The flow rate was $4 \mathrm{~mL} / \mathrm{min}$. After washing with ten column volumes of Buffer A1, the target glycoprotein was eluted in Buffer A2 (20 mM Tris- $\mathrm{HCl}, \mathrm{pH} 7.5,0.5 \mathrm{M}$ imidazole, and $0.5 \mathrm{M} \mathrm{NaCl}$ ). The eluent was concentrated with a $10 \mathrm{kDa}$ cut-off centrifugal filter (Merck, Darmstadt, Germany) to less than $10 \mathrm{~mL}$. The concentrated solution was separated through a Superdex 200 Prep Grade column (16 mm $\times 1000 \mathrm{~mm}$; GE Healthcare, Beijing, China) with phosphate-buffered saline (PBS) at a flow rate of $1 \mathrm{~mL} / \mathrm{min}$. The fractions were collected and analyzed by $12 \%$ SDS-PAGE.

\subsection{Lipopolysaccharide (LPS) and OPS Extraction}

LPS extraction was performed as described previously [35]. Briefly, the culture was collected by centrifugation and then resuspended in $\mathrm{ddH}_{2} \mathrm{O}$. After freezing and thawing, an equal volume of $90 \%$ phenol was added to each sample followed by vigorous shaking at $68^{\circ} \mathrm{C}$ and then centrifugation to collect the uppermost part of the supernatant (the water layer). The phenol layer was re-extracted with $\mathrm{ddH}_{2} \mathrm{O}$ and the previous step was repeated. The extracts were dialyzed into $\mathrm{ddH}_{2} \mathrm{O}$, then DNase (5 $\mu \mathrm{g} / \mathrm{mL}$; Solarbio, Beijing, China), RNase $(1 \mu \mathrm{g} / \mathrm{mL}$; Solarbio), and proteinase K (20 $\mu \mathrm{g} / \mathrm{mL}$; Merck) were sequentially added to the dialyzed samples and incubated the optimal temperature for each enzyme. After a boiling water bath for $10 \mathrm{~min}$, samples were centrifuged to obtain the LPS. 
Glacial acetic acid was added to the extracted LPS to achieve a final concentration of $1 \%(\mathrm{v} / \mathrm{v})$. After boiling for $90 \mathrm{~min}$, the $\mathrm{pH}$ of the LPS extract was adjusted to 7.0 with $\mathrm{NaOH}$. Finally, the mixture was centrifuged at $40,000 \times g$ for $5 \mathrm{~h}$, and the supernatant was collected as the OPS fraction.

\subsection{Animal Immunization Experiments}

Specific-pathogen-free female BALB/c mice were purchased from Charles River and housed in the Laboratory Animal Centre of the Academy of Military Medical Sciences at constant temperature and humidity. Water, food, and bedding were changed every 4 days. All animal experiments were approved by and conducted in accordance with the recommendations of the Animal Care and Use Committee of the Academy of Military Medical Sciences (ethics approval code IACUC-DWZX-2017-023, approved in November 2017).

Groups of 10 5-week-old BALB/c mice were used in the immunization experiments. Purified glycoproteins or OPS were diluted with PBS, and aluminum hydroxide adjuvant (General Chemical Corp, Brighton, MI, USA) was added to $10 \%$ of the final volume. Mice were immunized intraperitoneally (i.p.) with three doses (2.5 $\mu \mathrm{g}$ of the polysaccharides/mouse) at 2-week intervals and blood samples were collected by tail snip on the 10th day following the third dose. Mouse sera were separated from the blood and stored at $-20{ }^{\circ} \mathrm{C}$. Two weeks after the final immunization, mice were injected i.p. with different doses of A19 as described below, followed by determination of the bacterial load in the mouse spleens and monitoring of mouse survival.

\subsection{Enzyme-Linked Immunosorbent Assay (ELISA)}

A 96-well immunoplate was precoated with $10 \mu \mathrm{g} / \mathrm{mL}$ poly-L-lysine (100 $\mu \mathrm{L}$ per well). ELISA was performed as described previously [35]. Briefly, the 96-well immunoplate was coated for $2 \mathrm{~h}$ with diluted LPS at $37^{\circ} \mathrm{C}$ and then washed three times with Wash Buffer (PBS + 0.05\% Tween 20). The plates were patted dry and Blocking Buffer (PBS $+5 \%$ milk powder) was added to each well followed by incubation at $37^{\circ} \mathrm{C}$ for $2 \mathrm{~h}$. After drying the plates, diluted serum from the immunized mice was added to each well and the plate was incubated at $37^{\circ} \mathrm{C}$ for $1 \mathrm{~h}$. After another washing and drying step, 1:15,000 diluted HRP-conjugated goat anti-mouse IgG antibody (Abcam, Shanghai, China) was added to each well and incubated at $37^{\circ} \mathrm{C}$ for $1 \mathrm{~h}$. The washing and drying step was repeated. The Soluble TMB Kit (CWbio, Beijing, China) was used to initiate the detection reaction. Stop solution ( $2 \mathrm{M} \mathrm{H}_{2} \mathrm{SO}_{4}$ ) was added to each well to stop the reaction, and the absorbance of each well was measured at a wavelength of $490 \mathrm{~nm}$ with a microplate reader.

\subsection{Determination of Bacterial Loads in Spleens}

Mice were immunized and a non-lethal dose of B. abortus A19 was injected i.p. on the 14th day after the third immunization. On the 7th day post-infection, mice were sacrificed by neck dissection, and the spleens were removed and placed in $1.5 \mathrm{~mL}$ microcentrifuge tubes. The spleens were weighed and then homogenized with normal saline. After centrifugation at $5000 \times g$ for 10 min, the supernatant was discarded and the pellet was resuspended with normal saline. After repeating the previous step twice, the pellet was resuspended with $1 \mathrm{~mL}$ of $0.1 \%(\mathrm{w} / \mathrm{v})$ sodium deoxycholate. Finally, the bacterial suspension was diluted with normal saline and cultured on solid TSB medium. Bacterial colonies were counted after 2 days of culture at $37^{\circ} \mathrm{C}$.

\subsection{Determination of Cytokine Levels}

The cytokine levels of the immunized mice were determined with the Mouse TNF- $\alpha$ Precoated ELISA Kit, Mouse IL-1 $\beta$ Precoated ELISA Kit, Mouse IL-2 Precoated ELISA Kit, and Mouse IL-6 Precoated ELISA Kit (Dakewe, Shenzhen, China) in accordance with the manufacturer's instructions. Briefly, diluted serum samples and standards were added to the pre-coated wells, followed by the addition to each well of the biotinylated antibody relevant to the kit being used and incubation at $37^{\circ} \mathrm{C}$ for $90 \mathrm{~min}$. The wells were washed four times with Washing Buffer and patted dry, after which, 
Streptavidin-HRP was added to each well and the plates were incubated at $37^{\circ} \mathrm{C}$ for $30 \mathrm{~min}$. After another washing and drying step, TMB was added to each well and incubated at $37^{\circ} \mathrm{C}$ for $15 \mathrm{~min}$ shielded from the light, and the reactions were terminated using Stop solution. The absorbance of each well was measured at a wavelength of $450 \mathrm{~nm}$ with a microplate reader.

\subsection{Hematoxylin and Eosin (HE) Staining}

The livers and spleens of immunized mice were fixed with $4 \%$ paraformaldehyde (Solarbio, Beijing, China), and then paraffin-sectioned and stained using the Hematoxylin-Eosin (HE) Staining Kit (Solarbio) in accordance with the manufacturer's instructions. Briefly, the fixed samples were embedded and sectioned, then conventional dewaxing and hydration were performed. The tissue sections were stained with HE, after which, dehydration, cleaning for transparency, and neutral resin sealing were performed successively.

\subsection{Statistical Analysis}

Antibody titers were $\log _{2}$-transformed and bacterial loads were $\log _{10}$-transformed. Statistical analyses were conducted using GraphPad Prism version 7.0 (GraphPad, San Diego, CA, USA).

\section{Results}

\subsection{Application of the O-linked Glycosylation System in Y. Enterocolitica O:9}

Studies have reported that most polysaccharides are recognized by PglL [34], and our previous works demonstrated the successful use of PglL in some Gram-negative bacteria [35,38]. To create the conjugate vaccine against $B$. abortus with the $O$-linked glycosylation system, we first needed to verify that the OPS of B. abortus could be recognized by PglL. Y. enterocolitica O:9 strain 52212 (YeO9_52212) was used as the host cell because this low-pathogenicity strain has an identical OPS structure to that of B. abortus [37]. The pET-pglL-CTB4573H plasmid, from which PglL and rCTB [35] were co-expressed, or the pET-CTB4573H plasmid, from which rCTB alone was expressed, were introduced into YeO9_52212. After induction with IPTG and overnight culture, the total protein was extracted and separated by SDS-PAGE. Coomassie Blue staining and western blotting showed that the molecular weight (MW) of rCTB when expressed alone was only around $15 \mathrm{kDa}$ (Figure 1A). The MW of rCTB increased when PglL was co-expressed, indicating that rCTB might have been glycosylated. Further, two bands for rCTB were observed in YeO9_52212 cells expressing pET-pglL-CTB4573H. The lower band showed a slightly shifted MW compared with CTB4573H and the higher band had a MW between 35-40 kDa. These results indicated that the O-linked glycosylation system was efficiently expressed in YeO9_52212 and that almost all of the substrate protein had been glycosylated.

Glycoproteins were isolated by $\mathrm{Ni}^{2+}$ affinity and size exclusion chromatography (Figure S1). The recovery efficiency following purification was approximately $150 \mu \mathrm{g}$ polysaccharide/L medium. Anti-B. abortus and anti-Y. enterocolitica $0: 9$ specific monoclonal antibodies were used to test the structural similarity of OPS between Y. enterocolitica O:9 and B. abortus. The higher MW band of glycosylated CTB4573H (CTB-OPS ${ }_{\mathrm{Ba}}$ ) was detected by both antibodies, while the lower band was not observed because of the poor immunogenicity of short-chain OPS (Figure 1B). CTB naturally exists in a pentameric form [39]. To verify whether glycosylated CTB4573H was also in a polymeric state, we performed native gel electrophoresis. Coomassie Blue staining showed that the MW of $\mathrm{CTB}_{-O P S_{\mathrm{Ba}}}\left(\mathrm{C}-\mathrm{OPS}_{\mathrm{Ba}}\right)$ was around $242 \mathrm{kDa}$ (Figure 1C), which is approximately 5-fold that of the C-OPS ${ }_{\mathrm{Ba}}$ monomer $(\sim 40 \mathrm{kDa})$. Thus, $\mathrm{rCTB}$ could still pentamerize after glycosylation and purification. 
A

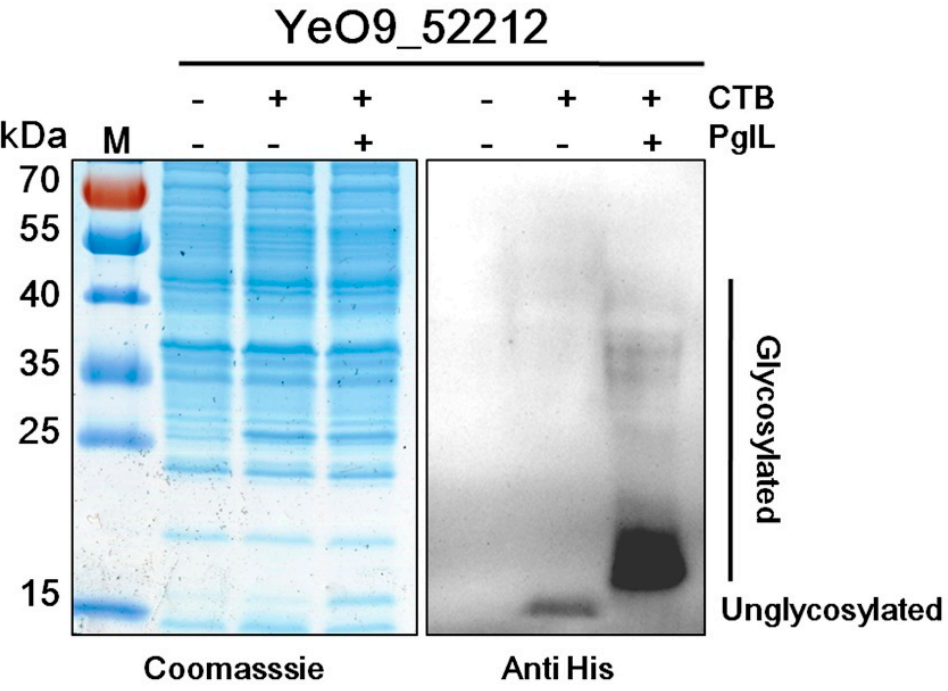

B
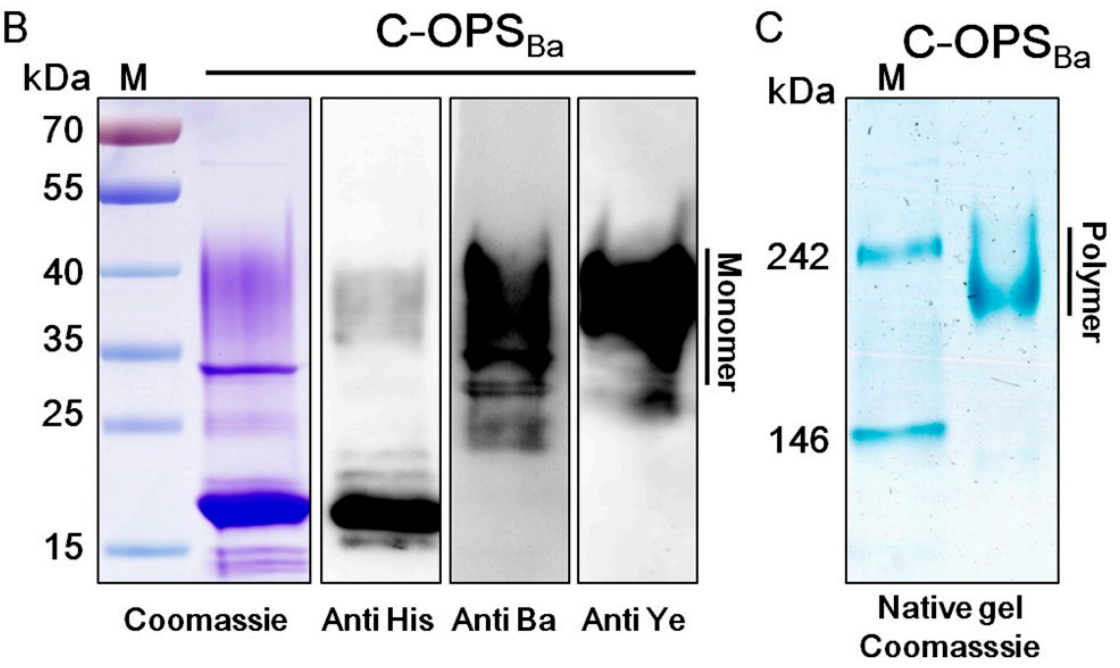

Figure 1. Analysis of glycosylated recombinant cholera toxin B subunit $(\mathrm{rCTB})$ and $\mathrm{CTB}-\mathrm{OPS} \mathrm{B}_{\mathrm{Ba}}$ expressed in YeO9_52212. (A) YeO9_52212 was transformed with pET-CTB4573H or pET-pgIL-CTB4573H and then induced with IPTG. A wild type strain was treated in the same way (negative control). Coomassie Blue staining (left) and western blotting (right) were performed. (B) The CTB-OPS $\mathrm{Ba}$ (C-OPS $\mathrm{Ba}$ ) glycoprotein was purified from strain YeO9_52212 co-expressing PglL and rCTB. Samples were separated by 12\% SDS-PAGE and analyzed by Coomassie Blue staining or western blotting using anti-His, anti-B. abortus (anti-Ba) or anti-Y. enterocolitica O:9 (anti-Ye) antibodies. (C) Coomassie Blue staining after native gel electrophoresis of C-OPS $\mathrm{Ba}$.

\subsection{Induction of Specific Antibody Responses in Mice}

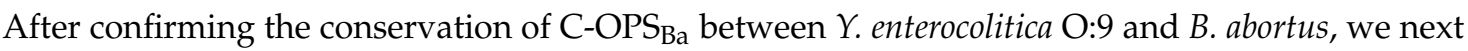
assessed the immunogenicity of $\mathrm{C}-\mathrm{OPS}_{\mathrm{Ba}}$ through a series of animal experiments. After a preliminary assessment of the safety of this vaccine obtained by measuring biochemical indicators including ALP, AST, ALT, and BUN (Figure S2), we tested the serum titers of antibodies against YeO9_52212 LPS following C-OPS $\mathrm{Ba}_{\mathrm{B}}$ immunization.

Ten 5-week-old BALB/c mice were immunized i.p. with either purified C-OPS $\mathrm{Ba}_{\mathrm{Ba}}$ or $\mathrm{OPS}_{\mathrm{Ba}}$ adjuvanted with aluminum hydroxide $\left(\mathrm{C}-\mathrm{OPS} \mathrm{Ba}_{\mathrm{Ba}}+\mathrm{Al}\right)$ on Days 0,14 , and 28 . Each group was immunized with the same quantity of polysaccharide $(2.5 \mu \mathrm{g} /$ mouse $)$ and another group was immunized with PBS only as a control. On the 10th day following the third immunization, serum was collected by tail snip and used to characterize IgG responses against YeO9_52212 LPS by ELISA. C-OPS $\mathrm{Ba}$ was observed 
to induce antibody titers against YeO9_52212 LPS in mice (Figure S3). We further detected specific antibodies against $B$. abortus LPS.

Purified C-OPS $S_{\mathrm{Ba}}$ and $\mathrm{OPS}_{\mathrm{Ba}}$ from YeO9_52212, with or without $10 \%$ aluminum hydroxide adjuvant $\left(\mathrm{C}-\mathrm{OPS}_{\mathrm{Ba}}, \mathrm{C}-\mathrm{OPS} \mathrm{Ba}_{\mathrm{Ba}}+\mathrm{Al}, \mathrm{OPS}_{\mathrm{Ba}}, \mathrm{OPS}_{\mathrm{Ba}}+\mathrm{Al}\right)$, were used for immunization as described above. ELISA results showed that $B$. abortus LPS-specific IgG titers in all groups were elevated compared with the PBS-vaccinated group, especially in $\mathrm{C}-\mathrm{OPS}_{\mathrm{Ba}}$ - and $\mathrm{C}-\mathrm{OPS} \mathrm{Ba}_{\mathrm{a}}+\mathrm{Al}$-vaccinated mice. The titer in the $\mathrm{C}_{-} \mathrm{OPS}_{\mathrm{Ba}}$ group was significantly higher than the titers of the $\mathrm{OPS}_{\mathrm{Ba}}$ and $\mathrm{OPS}_{\mathrm{Ba}}+\mathrm{Al}$ groups but similar to that of the C-OPS $\mathrm{Ba}+\mathrm{Al}$ group (Figure 2A). We further detected IgG subclass titers (IgG1, IgG2a, IgG2b, and IgG3) against B. abortus A19 LPS in the sera of PBS-, $\mathrm{OPS}_{\mathrm{Ba}^{-}}$, and C-OPS $\mathrm{Ba}^{-}$-vaccinated mice. Apart from the IgG3 titers, other subclass titers in the C-OPS $\mathrm{Ba}_{\mathrm{B}}$ group were significantly higher than in the PBS group (Figure 2B).

A

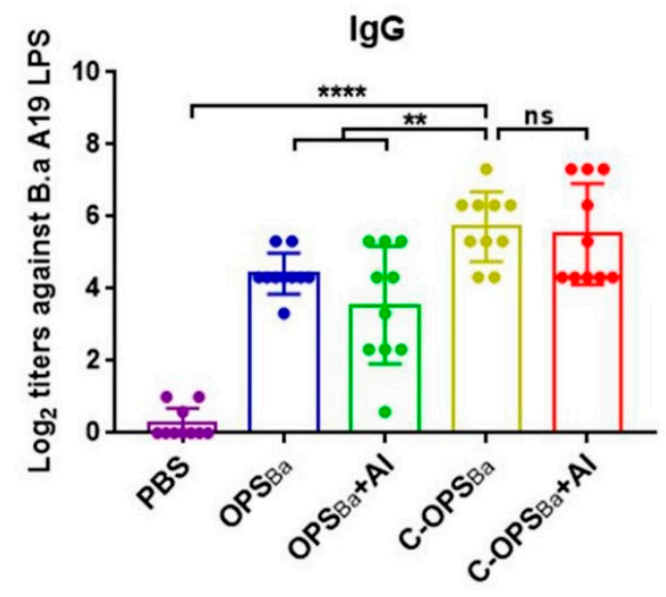

B

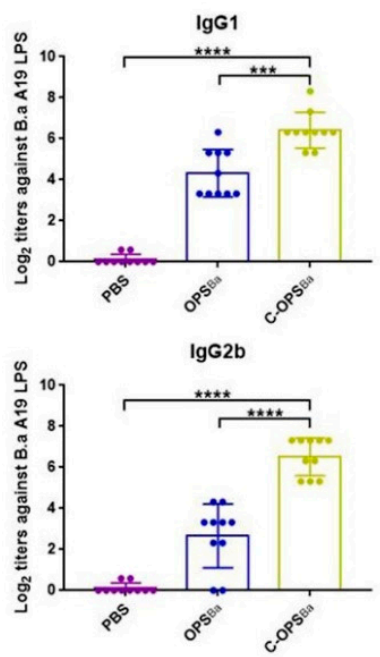

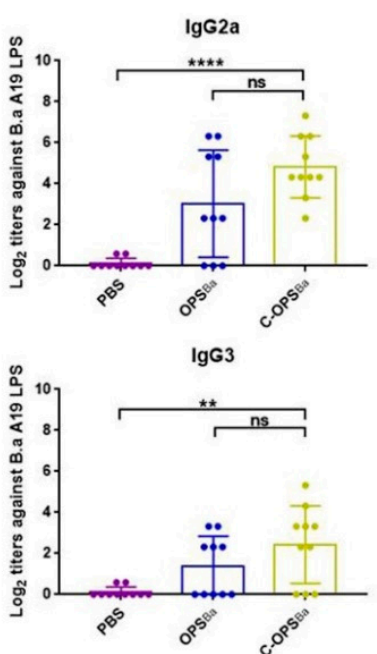

Figure 2. IgG responses against B. abortus A19 lipopolysaccharide (LPS). (A) IgG titers against A19 LPS

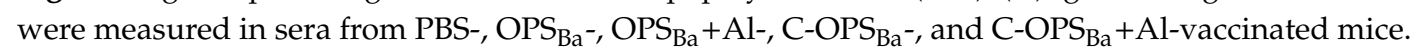
(B) IgG subclass titers (IgG1, IgG2a, IgG2b, and IgG3) against A19 LPS were measured in sera from

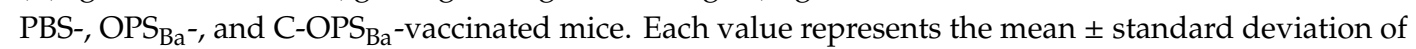
$\log _{2}$-transformed titers in the sera of individual mice (shown as data points on the graphs) from each group $(n=10)$. The unpaired $t$-test was used to evaluate differences between IgG titers $(* *, p<0.01$; $* * * *, p<0.0001 ;$ ns, no statistically significant difference).

\subsection{Evaluation of Vaccine-Induced Protection in Mice following Infection with a Non-Lethal dose of B. Abortus}

Given the success of the bioconjugate vaccine in eliciting both Y. enterocolitica O:9 and B. abortus LPS-specific IgG antibodies, we further evaluated the protective effects of this vaccine against non-lethal infection. For traditional live attenuated vaccines against $B$. abortus, the virulent smooth strain of B. abortus has to be used to evaluate the protective effects (mainly through measurement of the clearance rate of bacteria in the mouse spleen). In contrast, there is no unified evaluation standard for the bioconjugate type of vaccines, and preliminary evaluation of their protective effect can be evaluated through infection with the $B$. abortus hypovirulent smooth strain. Fourteen days after the third immunization, mice were challenged with a non-lethal dose $\left(1.03 \times 10^{7} \mathrm{CFU} /\right.$ mouse $)$ of B. abortus hypovirulent strain A19 (A19). For all treatment groups, the TNF- $\alpha$ levels began to decline after reaching a peak on the 5th day (Figure 3A). Serum TNF- $\alpha$ levels in the PBS-immunized group and the $\mathrm{OPS}_{\mathrm{Ba}}$ - and $\mathrm{OPS}_{\mathrm{Ba}}+\mathrm{Al}$-immunized groups increased markedly following infection. In contrast, C-OPS $\mathrm{Ba}$ and $\mathrm{C}-\mathrm{OPS} \mathrm{Ba}_{\mathrm{a}}+\mathrm{Al}$ vaccination significantly inhibited the production of TNF- $\alpha$, and TNF- $\alpha$ levels in the $\mathrm{C}-\mathrm{OPS}_{\mathrm{Ba}}$ group were lower than those in the $\mathrm{C}-\mathrm{OPS}_{\mathrm{Ba}}+\mathrm{Al}$ group. We also measured serum IL-1 $\beta$, IL-2, and IL-6 levels in the immunized mice but no significant differences in expression were detected. 
A

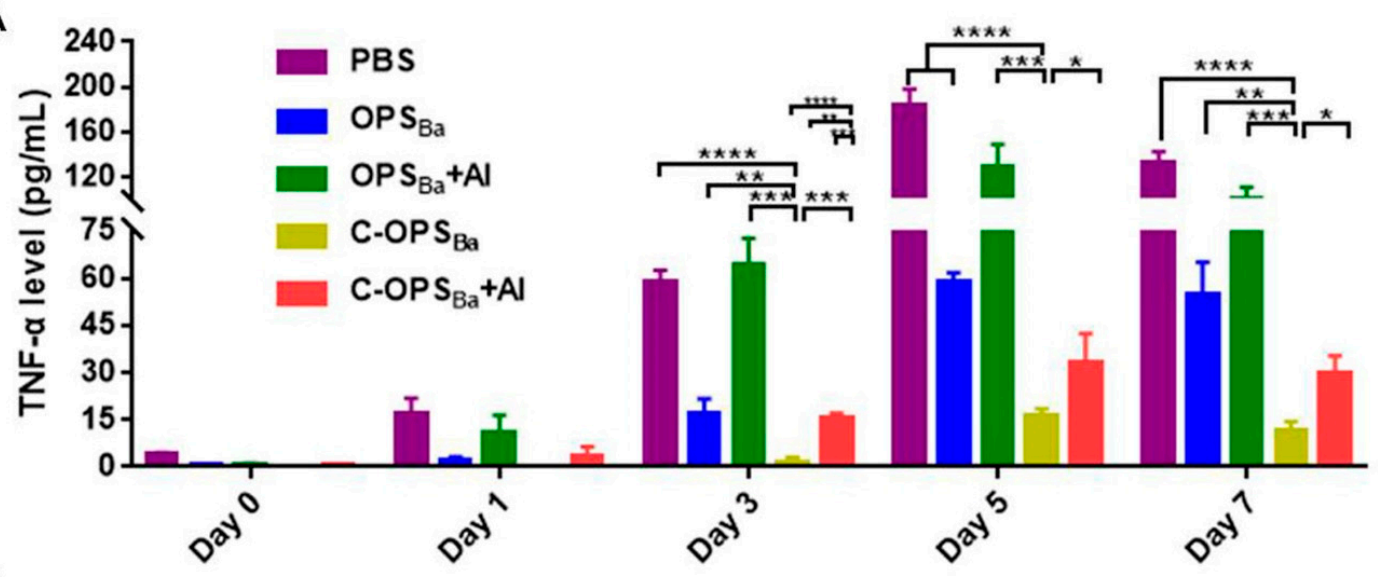

B

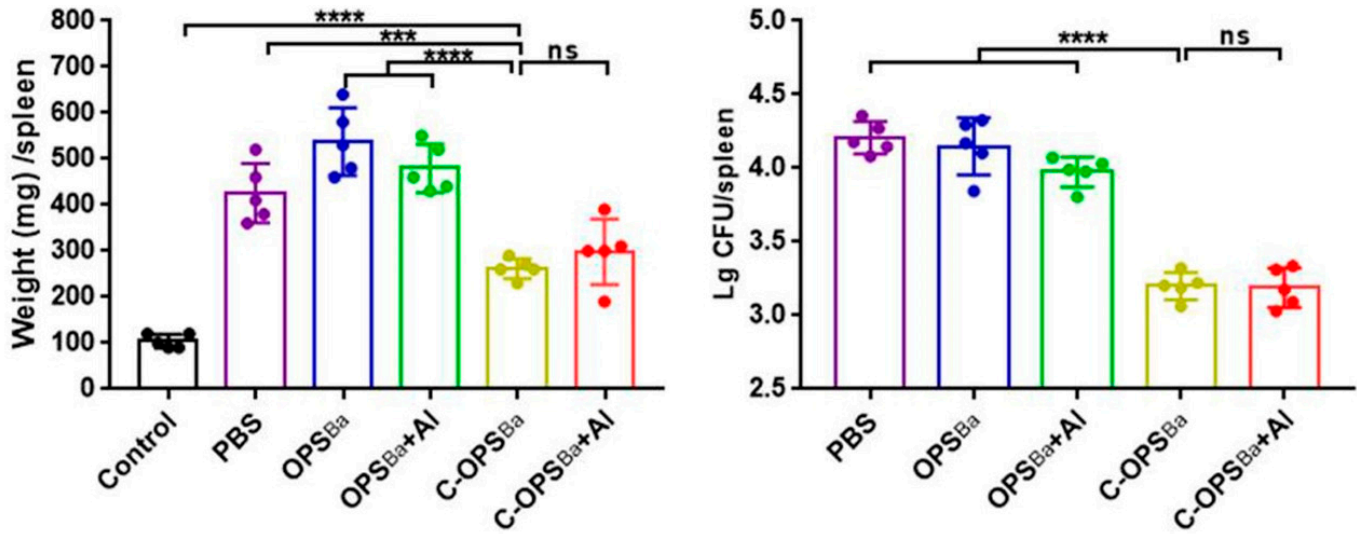

C

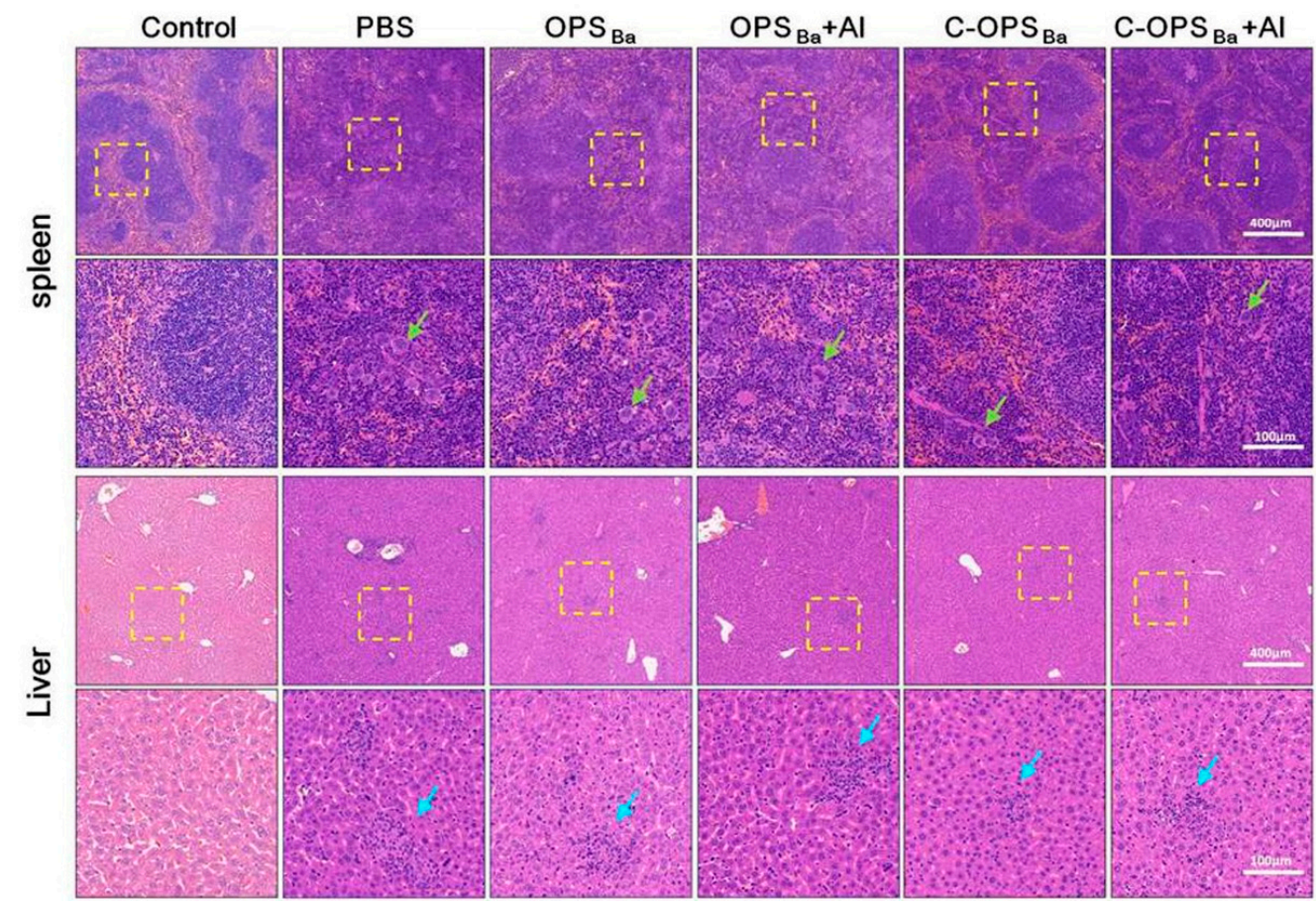

Figure 3. Immune responses of mice following non-lethal B. abortus A19 infection. Immunized mice were infected intraperitoneally with $1.03 \times 10^{7} \mathrm{CFU}$ of A19 on the 14th day following the third immunization. As a control, another group of naive mice was injected intraperitoneally with normal saline. (A) After infection, the sera of mice in each group were collected on the 1st, 3rd, 5th, and 7th day 
and the TNF- $\alpha$ levels were measured. The unpaired $t$-test was used to evaluate differences between TNF- $\alpha$ levels at different time points. Each value represents the mean \pm standard deviation $(n=3)$. (B) On the 7th day post-infection, mouse spleens were collected and weighed and the bacterial loads were measured. Each value represents the mean \pm standard deviation of spleen weight or $\log _{10}$-transformed bacterial loads (CFU/spleen) of individual mice (shown as data points on the graphs) from each group ( $n=5$ per group). The unpaired $t$-test was used to evaluate differences between spleen weights or bacterial loads $\left(* * *, p<0.001 ;{ }^{* * * *}, p<0.0001 ; \mathrm{ns}\right.$, no statistically significant difference). (C) The livers and spleens of infected mice and normal mice (Control) were fixed with $4 \%$ paraformaldehyde, paraffin sectioned, and then stained with hematoxylin and eosin. The yellow boxes in the top panels represent the field of view in the corresponding figures below, which were magnified four times. Green arrows indicate multinucleated giant cells and blue arrows indicate hyperplastic nodules.

Seven days following infection, the mice were dissected and their spleens were removed. We found that the spleen size had increased following infection, with a significant increase in the spleen weight in the PBS group compared with the C-OPS $\mathrm{Ba}$ group, and in the $\mathrm{OPS}_{\mathrm{Ba}}$ group compared with the control group (Figure S4 and Figure $3 \mathrm{~B}$ ). We enumerated the bacteria in each spleen and observed approximately $10^{3}-10^{3.5} \mathrm{CFU}$ of $\mathrm{A} 19$ in $\mathrm{C}^{-} \mathrm{OPS}_{\mathrm{Ba}}$ and $\mathrm{C}-\mathrm{OPS}_{\mathrm{Ba}}+\mathrm{Al}$-vaccinated mice. In contrast, the bacterial loads of other groups remained around $10^{4}-10^{4.5} \mathrm{CFU}$ in the spleen, which was significantly higher than those of mice immunized with $\mathrm{C}-\mathrm{OPS} \mathrm{Ba}_{\mathrm{a}}$ and $\mathrm{C}-\mathrm{OPS}_{\mathrm{Ba}}+\mathrm{Al}$ (Figure 3B). These results indicated that mice immunized with $\mathrm{C}-\mathrm{OPS} \mathrm{Ba}_{\mathrm{Ba}}$ and $\mathrm{C}-\mathrm{OPS} \mathrm{Ba}_{\mathrm{Ba}}+\mathrm{Al}$ were effectively protected against invading pathogens and the resulting lethal cytokine storms.

Spleens and livers were paraffin-sectioned and stained with HE. Compared with the control mice, the immunized mice showed different degrees of pathological changes in their spleens and livers. The spleens of all vaccinated mice with low-spectroscopy observation showed an increase in the white pulp, reflecting the proliferation of lymphocytes. Multinucleated giant cells with varying numbers and shapes of nuclei caused by foreign bodies increased with high-spectroscopy observation (green arrows) (Figure 3C). The livers showed an aggregation of lymphocytes under low-spectroscopy observation and hyperplastic nodules caused by Brucella were seen under high-spectroscopy observation (blue arrows) (Figure 3C). Spleen and liver damage were most severe in mice immunized with PBS, followed by $\mathrm{OPS}_{\mathrm{Ba}}$ and $\mathrm{OPS}_{\mathrm{Ba}}+\mathrm{Al}$. This damage was mildest in the C-OPS $\mathrm{Ba}_{\mathrm{Ba}}$ and $\mathrm{C}-\mathrm{OPS} \mathrm{Ba}_{\mathrm{Ba}}+\mathrm{Al}$ groups, especially the $\mathrm{C}-\mathrm{OPS}_{\mathrm{Ba}}$ group (Figure $3 \mathrm{C}$ ).

\subsection{Evaluation of Protection against the Lethal dose Challenge}

After demonstrating the safety and efficacy of the vaccine against non-lethal infection, we next evaluated its protective efficacy against lethal challenge. Separate groups of mice were immunized with PBS, OPS $\mathrm{Ba}, \mathrm{OPS}_{\mathrm{Ba}}+\mathrm{Al}, \mathrm{C}-\mathrm{OPS} \mathrm{Ba}_{\mathrm{B}}$, or C-OPS $\mathrm{Ba}+\mathrm{Al}$ as described previously and challenged with a lethal dose of A19 (Figure 4A). Mice were challenged i.p. with approximately $3 \times \mathrm{LD}_{50}$ of A19 $\left(1.54 \times 10^{8} \mathrm{CFU} /\right.$ mouse $) 2$ weeks after the last vaccination, and survival was monitored for up to 14 days. All of the PBS-vaccinated mice died within 2 days and the 2-week survival rates in the OPS and $\mathrm{OPS}_{\mathrm{Ba}}+\mathrm{Al}$ groups were no more than $60 \%$. In contrast, vaccination with C-OPS $\mathrm{Ba}$ or C-OPS $\mathrm{Ba}+\mathrm{Al}$ provided $100 \%$ protection without the adjuvant (Figure $4 \mathrm{~B}$ ). These results demonstrated that the administration of $\mathrm{C}-\mathrm{OPS} \mathrm{Ba}_{\mathrm{a}}$ was far more effective than $\mathrm{OPS}_{\mathrm{Ba}}$ in protecting mice against lethal challenge with $B$. abortus. These findings were consistent with previous studies.

To verify the stability of the protective effect of C-OPS $\mathrm{Ba}_{\mathrm{B}}$ in mice, we immunized another three groups of mice with PBS, C-OPS $\mathrm{Ba}$ or $\mathrm{C}-\mathrm{OPS}_{\mathrm{Ba}}+\mathrm{Al}$ as described above to assess their survival rate following a higher lethal dose challenge $\left(2.51 \times 10^{8} \mathrm{CFU} /\right.$ mouse, $\left.5 \times \mathrm{LD}_{50}\right)$. With this higher challenge dose, the survival rate of the mice was $90 \%$ for the C-OPS $\mathrm{Ba}^{-}$and C-OPS $\mathrm{Ba}_{\mathrm{a}}+\mathrm{Al}$-vaccinated mice (Figure $4 \mathrm{C}$ ), indicating that $\mathrm{C}-\mathrm{OPS}_{\mathrm{Ba}}$ can induce potent protection in mice. The IgG titers against A19 LPS in the sera of these mice were then measured. There was a significant difference in titer between the $\mathrm{C}-O P S_{\mathrm{Ba}}$ - and PBS-vaccinated mice (Figure S5A). Finally, immunized mice were infected with an even higher dose of A19 (lethal to $20 \%$ of PBS-vaccinated mice). The C-OPS $\mathrm{Ba}$ - and C-OPS $\mathrm{Ba}+\mathrm{Al}$-vaccinated 
mice showed significantly lower bacterial loads in the spleen compared with PBS-vaccinated mice (Figure $\mathrm{S5B}$ ). These results indicated that $\mathrm{C}-\mathrm{OPS}_{\mathrm{Ba}}$ can induce stable protection in mice.

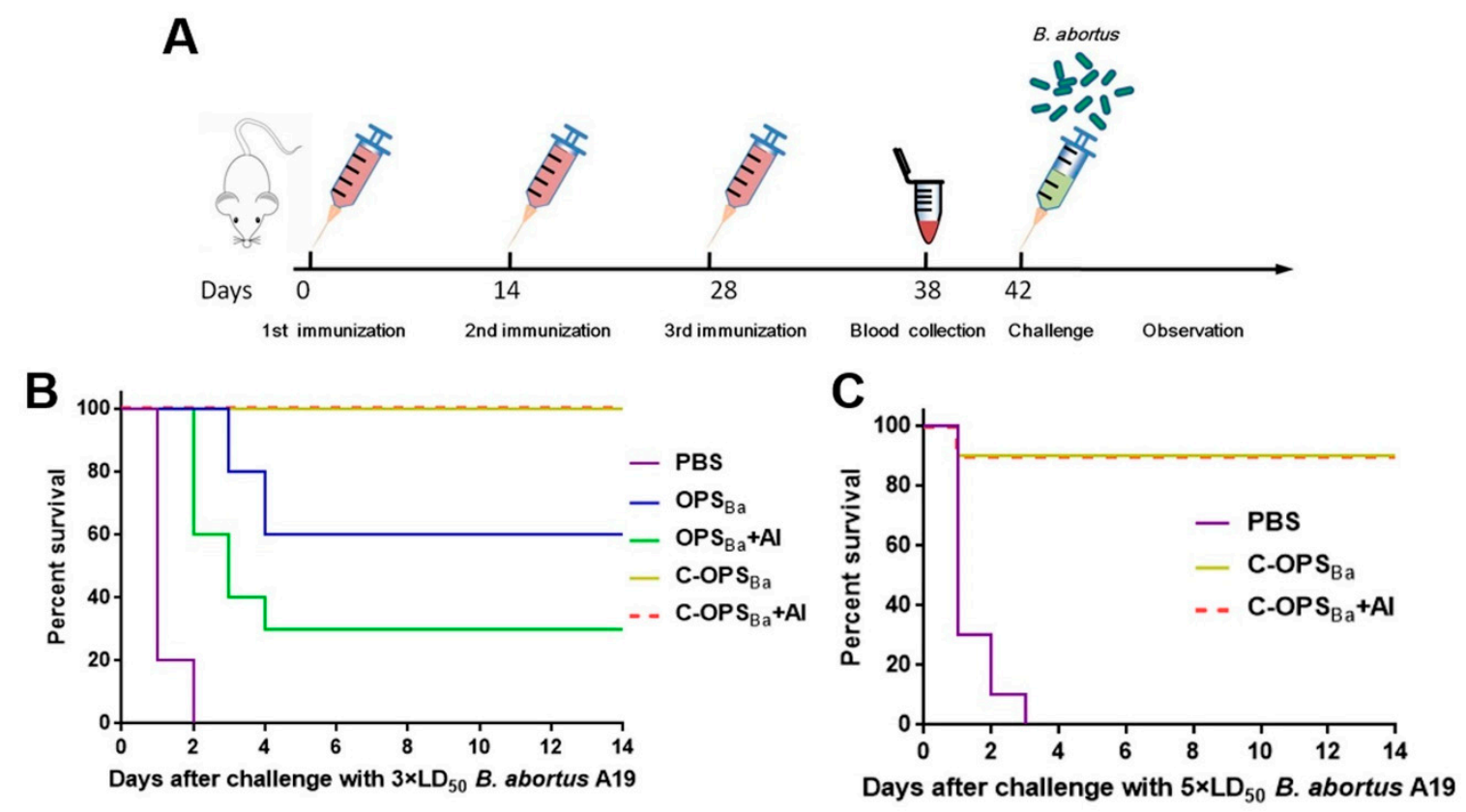

Figure 4. Survival of BALB/c mice after challenge with a lethal dose of B. abortus A19. Mice were challenged 2 weeks after final immunization by intraperitoneal injection with different doses of A19 and survival was monitored. (A) Schematic diagram of the challenge experiment. (B) Mice were immunized with PBS, OPS $\mathrm{Ba}, \mathrm{OPS}_{\mathrm{Ba}}+\mathrm{Al}, \mathrm{C}-\mathrm{OPS}_{\mathrm{Ba}}$ or $\mathrm{C}-\mathrm{OPS}_{\mathrm{Ba}}+\mathrm{Al}$ and challenged with $\sim 1.54 \times 10^{8} \mathrm{CFU} / \mathrm{mouse}$ $\left(3 \times \mathrm{LD}_{50}\right)$ of $\mathrm{A} 19(n=10)$. (C) Mice were immunized with $\mathrm{C}-\mathrm{OPS}_{\mathrm{Ba}}, \mathrm{C}-\mathrm{OPS}_{\mathrm{Ba}}+\mathrm{Al}$ or PBS then challenged with approximately $2.51 \times 10^{8} \mathrm{CFU} /$ mouse $\left(5 \times \mathrm{LD}_{50}\right)$ of $\mathrm{A} 19(n=10)$.

\section{Discussion}

In this study, we developed a novel bioconjugate vaccine candidate against $B$. abortus based on a bacterial O-linked glycosylation system. YeO9_52212 was engineered to act as the host organism for the production of the bioconjugate vaccine against B. abortus. Because YeO9_52212 is less pathogenic and more easily cultured than $B$. abortus, we were able to avoid the large-scale culture of highly pathogenic bacteria. Our results demonstrated that $\mathrm{C}-\mathrm{OPS}_{\mathrm{Ba}}$ induced strong immune responses against $\mathrm{B}$. abortus even in the absence of the aluminum hydroxide adjuvant.

We chose OPS as the target for vaccine development because of its ability to elicit antibodies that can confer protection against infection [40]. The glycoprotein generated in YeO9_52212 was able to induce antibodies against $B$. abortus as a result of the similarity in OPS between these two bacterial species [37]. The OPS of Brucella spp. is a homopolymer of $N$-formyl-perosamine (4-formamido-4,6-dideoxy D-mannose) with various proportions of $\alpha-(1 \rightarrow 2)$ and $\alpha-(1 \rightarrow 3)$-linkages and it has three antibody reactivities ( $\mathrm{A}, \mathrm{M}$, and $\mathrm{C}$ ). The $\mathrm{A}$ epitope corresponds to five or more continuous sugar units with $\alpha-(1 \rightarrow 2)$ linkages and is typical of some B. abortus and B. suis biovars. The $\mathrm{M}$ epitope corresponds to the pentasaccharide with four $\alpha-(1 \rightarrow 2)$-linked and one $\alpha-(1 \rightarrow 3)$-linked polymers of the same sugar and is characteristic of $B$. melitensis. The $\mathrm{C}$ epitope represents the ratio of $\mathrm{A} / \mathrm{M}$ reactivities highly repeated in the OPS of all biovars [2,23]. B. abortus contains $\sim 98 \%$ of the A epitope, B. suis has a unique $1: 7$ ratio of $\alpha-(1 \rightarrow 3)$ - to $\alpha-(1 \rightarrow 2)$-linked polymers, and $B$. melitensis has only the $\mathrm{M}$ epitope of the pentasaccharide repeating unit [2]. Y. enterocolitica O:9 generates strong cross-reactivity with Brucella as its OPS is a homopolymer of $N$-formyl-perosamine with exclusively $\alpha-(1 \rightarrow 2)$-linkages [2,22]. It is thus reasonable to speculate that the bioconjugate vaccine produced in YeO9_52212 would induce cross-reactive immune responses against $B$. suis and B. melitensis. Cross-protection against $B$. suis or B. melitensis remains to be verified, and this could further expand the scope of vaccine application. 
Although the use of AcrA as a carrier protein failed to exert a protective effect in mice against B. abortus infection in a previous report, the feasibility of the use of carriers proteins as part of the B. abortus vaccine preparation strategy was demonstrated [22]. Since carrier proteins play an important role in immune response, protein toxins such as the tetanus toxoid, the recombinant exotoxin A protein from Pseudomonas aeruginosa (rEPA), the diphtheria toxoid, and rCTB used in the present study, are usually included in the vaccine design for better stimulation of the immune system [24]. Our previous studies found that different carrier proteins have different immune effects, and we demonstrated that the use of rCTB in bioconjugate vaccines conferred superior protection against Shigella flexneri and Salmonella enterica serovar Paratyphi A than rEPA, another commonly used carrier protein $[35,38]$. The bioconjugate vaccine in the present study used $\mathrm{rCTB}$ and exhibited a potent immune effect that was probably attributable to the good immunoadjuvant properties of CTB itself [39], as CTB has been shown to induce anti-inflammatory responses and regulate T-cell immune responses [41]. In addition, the rCTB pentamer can form more complex spatial structures, which facilitates activation of the immune response. We found that protein glycosylation did not change the pentameric structure of the substrate rCTB protein, as shown by the native PAGE results in this study. This finding also suggested that the size, structure, charge, and other physical/chemical properties of carrier proteins should be considered for the rational design of vaccines in the future.

Because there is no clear and unified evaluation model for Brucella vaccines, we used TNF- $\alpha$ as an indicator of the protective effect of the vaccine. TNF- $\alpha$ is one of the most important proinflammatory cytokines, and its secretion is associated with inflammatory responses caused by infection. TNF- $\alpha$ is one of the first cytokines released by macrophages following B. abortus infection, and its production results from direct interactions between Brucella and macrophages [42]. TNF- $\alpha$ plays a crucial role in enhancing IL-12 production [23], and depletion of IL-12 leads to decreased production of interferon- $\gamma$ and nitric oxide, resulting in exacerbation of infection $[23,42]$. Here, the serum TNF- $\alpha$ levels in mice

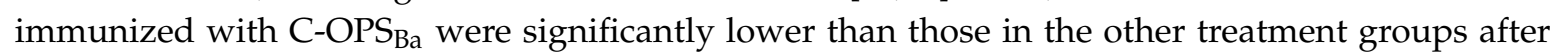
infection with B. abortus. Infection via the intraperitoneal route can induce a strong inflammatory response. There was a higher level of recall response in the C-OPS $\mathrm{Ba}$-vaccinated group because of pre-existing protective antibodies, which could quickly neutralize and kill the invading pathogens, such that the bacterial loads in the spleen were significantly reduced. Because the pathogen could be rapidly cleared, there was no strong immune response; in contrast, the mouse spleens were enlarged in the PBS- and $\mathrm{OPS}_{\mathrm{Ba}}$-immunized groups, with a significantly increased proportion of white pulp observed.

The two most common routes of human infection for Brucellosis are the ingestion of contaminated dairy products or inhalation of contaminated aerosols. This leads to Brucella colonization of organs such as the spleen, liver, and lymph nodes. Owing to its potential spread by aerosols, Brucella has been classified as a biological threat [43]. This poses a risk during the production of live attenuated vaccines, requiring stricter production requirements and resulting in higher production costs. Thus, the live attenuated vaccines could lead to the possibility of leakage contamination. Research and development of new candidate vaccines are urgently required. Our study provides a conceptual advance for vaccine production against B. abortus - not only is the described production process safer and more economical than that used for traditional live attenuated vaccines, but our strategy also avoids the potential risk of virulence reversion and antibiotic resistance. Our conjugate vaccine could also be used to diagnose brucellosis [22]. In addition, subunit vaccines make it easy to distinguish between immunization and natural infection in animals. To further improve safety, in future studies we will delete the virulence-related genes of the YeO9_52212 engineered bacteria to render it even more suitable for industrial production.

Supplementary Materials: The following are available online at http://www.mdpi.com/2076-2607/8/3/436/s1,

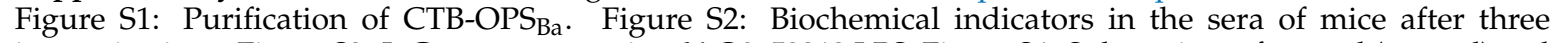
immunizations. Figure S3: IgG responses against YeO9_52212 LPS. Figure S4: Spleen sizes of control (normal) and immunized mice following infection with B. abortus A19. Figure S5: IgG responses against B. abortus A19 LPS and bacterial loads in the spleens of PBS-, C-OPS $\mathrm{Ba}^{-}$, and C-OPS $\mathrm{Ba}+\mathrm{Al}$-vaccinated mice following infection with a higher dose of B. abortus A19. 
Author Contributions: Conceptualization and experiments, J.H. and C.P.; Methodology, P.S. and J.W.; Software, J.H.; Validation, C.P., L.Z. and H.W.; Formal Analysis, J.H.; Investigation, C.P.; Resources, E.F.; Data Curation, J.H.; Writing - Original Draft Preparation, J.H. and C.P.; Writing - Review \& Editing, L.Z. and H.W.; Visualization, H.W.; Supervision, J.W., L.Z. and H.W.; Project Administration, L.Z. and H.W.; Funding Acquisition, H.W. All authors have read and agreed to the published version of the manuscript.

Funding: This work was supported by the National Natural Science Foundation of China (grant nos. 31700802, 81930122, and 81871314).

Acknowledgments: We thank Huaiqi Jing and Xin Wang from the Chinese Center for Disease Control and Prevention for providing strains and discussions. We thank Natasha Beeton-Kempen, from Liwen Bianji, Edanz Editing China (www.liwenbianji.cn/ac), for editing the English text of a draft of this manuscript.

Conflicts of Interest: The authors declare no conflict of interest.

\section{References}

1. Olsen, S.C.; Palmer, M.V. Advancement of Knowledge of Brucella Over the Past 50 Years. Veter- Pathol. 2014, 51, 1076-1089. [CrossRef] [PubMed]

2. Ciocchini, A.E.; Serantes, D.A.R.; Melli, L.J.; Iwashkiw, J.A.; Deodato, B.; Wallach, J.; Feldman, M.F.; Ugalde, J.E.; Comerci, D.J. Development and Validation of a Novel Diagnostic Test for Human Brucellosis Using a Glyco-engineered Antigen Coupled to Magnetic Beads. PLOS Negl. Trop. Dis. 2013, 7, e2048. [CrossRef] [PubMed]

3. Pappas, G. The changing Brucella ecology: Novel reservoirs, new threats. Int. J. Antimicrob. Agents 2010, 36, S8-S11. [CrossRef] [PubMed]

4. Pandey, A.; Cabello, A.; Akoolo, L.; Rice-Ficht, A.; Arenas-Gamboa, A.; McMurray, D.; Ficht, T.A.; De Figueiredo, P. The Case for Live Attenuated Vaccines against the Neglected Zoonotic Diseases Brucellosis and Bovine Tuberculosis. PLOS Negl. Trop. Dis. 2016, 10, 0004572. [CrossRef]

5. Pappas, G.; Papadimitriou, P.; Akritidis, N.; Christou, L.; Tsianos, E.V. The new global map of human brucellosis. Lancet Infect. Dis. 2006, 6, 91-99. [CrossRef]

6. Kumar, A. Brucellosis: Need of public health intervention in rural India. Prilozi 2010, 31, 219-231.

7. Hotez, P.J.; Gurwith, M. Europe's Neglected Infections of Poverty. Int. J. Infect. Dis. 2011, 15, e611-e619. [CrossRef]

8. Ducrotoy, M.J.; Conde-Alvarez, R.; Blasco, J.M.; Moriyon, I. A review of the basis of the immunological diagnosis of ruminant brucellosis. Veter- Immunol. Immunopathol. 2016, 171, 81-102. [CrossRef]

9. Sadeghi, Z.; Fasihi-Ramandi, M.; Bouzari, S. Evaluation of immunogenicity of novel multi-epitope subunit vaccines in combination with poly I:C against Brucella melitensis and Brucella abortus infection. Int. Immunopharmacol. 2019, 75, 105829. [CrossRef]

10. Ariza, J.; Bosilkovski, M.; Cascio, A.; Colmenero, J.D.; Corbel, M.J.; E Falagas, M.; Memish, Z.A.; Roushan, M.R.H.; Rubinstein, E.; Sipsas, N.V.; et al. Perspectives for the Treatment of Brucellosis in the 21st Century: The Ioannina Recommendations. PLoS Med. 2007, 4, e317. [CrossRef]

11. Avila-Calderón, E.D.; Lopez-Merino, A.; Sriranganathan, N.; Boyle, S.M.; Contreras-Rodríguez, A. A History of the Development of Brucella Vaccines. BioMed Res. Int. 2013, 2013, 1-8. [CrossRef] [PubMed]

12. Dorneles, E.M.S.; Sriranganathan, N.; Lage, A.P. Recent advances in Brucella abortus vaccines. Veter- Res. 2015, 46, 76. [CrossRef]

13. Conde-Alvarez, R.; Gorvel, J.-P.; Gil-Ramírez, Y.; Iriarte, M.; Grillo, M.-J.; Gorvel, J.-P.; Moriyon, I. Lipopolysaccharide as a target for brucellosis vaccine design. Microb. Pathog. 2013, 58, 29-34. [CrossRef] [PubMed]

14. Wang, Z.; Niu, J.R.; Wang, X.L.; Wu, T.L.; Cheng, J.; Lu, L.; Wu, Q.M. Evaluation of a Brucella melitensis mutant deficient in O-polysaccharide export system ATP-binding protein as a rough vaccine candidate. Microbes Infect. 2014, 16, 633-639. [CrossRef] [PubMed]

15. Hop, H.T.; Arayan, L.T.; Huy, T.X.N.; Reyes, A.W.B.; Min, W.; Lee, H.J.; Park, S.J.; Chang, H.-H.; Kim, S. Immunization of BALB/c mice with a combination of four recombinant Brucella abortus proteins, AspC, Dps, InpB and Ndk, confers a marked protection against a virulent strain of Brucella abortus. Vaccine 2018, 36, 3027-3033. [CrossRef] [PubMed] 
16. Delpino, M.V.; Estein, S.M.; Fossati, C.A.; Baldi, P.; Cassataro, J. Vaccination with Brucella recombinant DnaK and SurA proteins induces protection against Brucella abortus infection in BALB/c mice. Vaccine 2007, 25, 6721-6729. [CrossRef]

17. Yu, D.H.; Hu, X.D.; Cai, H. A Combined DNA Vaccine Encoding Bcsp31, Sod, and L7/L12 Confers High Protection against Brucella Abortus 2308 by Inducing Specific Ctl Responses. DNA Cell Biol. 2007, 26, 435-443. [CrossRef]

18. Ficht, T.A.; Kahl-McDonagh, M.M.; Arenas-Gamboa, A.M.; Rice-Ficht, A.C. Brucellosis: The case for live, attenuated vaccines. Vaccine 2009, 27, D40-D43. [CrossRef]

19. Vishnu, U.S.; Sankarasubramanian, J.; Gunasekaran, P.; Rajendhran, J. Identification of potential antigens from non-classically secreted proteins and designing novel multitope peptide vaccine candidate against Brucella melitensis through reverse vaccinology and immunoinformatics approach. Infect. Genet. Evol. 2017, 55, 151-158. [CrossRef]

20. Perkins, S.D.; Smither, S.J.; Atkins, H.S. Towards aBrucellavaccine for humans. FEMS Microbiol. Rev. 2010, 34, 379-394. [CrossRef]

21. Mostowy, R.J.; Holt, K.E. Diversity-Generating Machines: Genetics of Bacterial Sugar-Coating. Trends Microbiol. 2018, 26, 1008-1021. [CrossRef]

22. A Iwashkiw, J.; Fentabil, M.A.; Faridmoayer, A.; Mills, D.C.; Peppler, M.S.; Czibener, C.; Ciocchini, A.E.; Comerci, D.J.; Ugalde, J.E.; Feldman, M.F. Exploiting the Campylobacter jejuni protein glycosylation system for glycoengineering vaccines and diagnostic tools directed against brucellosis. Microb. Cell Factories 2012, 11, 13. [CrossRef] [PubMed]

23. Dorneles, E.M.; Teixeira-Carvalho, A.; Araújo, M.S.; Sriranganathan, N.; Lage, A.P. Immune response triggered by Brucella abortus following infection or vaccination. Vaccine 2015, 33, 3659-3666. [CrossRef] [PubMed]

24. Berti, F.; Adamo, R. Antimicrobial glycoconjugate vaccines: An overview of classic and modern approaches for protein modification. Chem. Soc. Rev. 2018, 47, 9015-9025. [CrossRef] [PubMed]

25. Harding, C.M.; Feldman, M.F. Glycoengineering bioconjugate vaccines, therapeutics, and diagnostics in E. coli. Glycobiology 2019, 29, 519-529. [CrossRef] [PubMed]

26. Hug, I.; Feldman, M.F. Analogies and homologies in lipopolysaccharide and glycoprotein biosynthesis in bacteria. Glycobiology 2010, 21, 138-151. [CrossRef]

27. Colombo, C.; Pitirollo, O.; Lay, L. Recent Advances in the Synthesis of Glycoconjugates for Vaccine Development. Molecules 2018, 23, 1712. [CrossRef]

28. Wacker, M.; Linton, D.; Hitchen, P.G.; Nita-Lazar, M.; Haslam, S.; North, S.J.; Panico, M.; Morris, H.R.; Dell, A.; Wren, B.W.; et al. N-Linked Glycosylation in Campylobacter jejuni and Its Functional Transfer into E. coli. Science 2002, 298, 1790-1793. [CrossRef]

29. Ihssen, J.; Kowarik, M.; Dilettoso, S.; Tanner, C.; Wacker, M.; Thöny-Meyer, L. Production of glycoprotein vaccines in Escherichia coli. Microb. Cell Factories 2010, 9, 61. [CrossRef]

30. Marshall, L.E.; Nelson, M.; Davies, C.H.; Whelan, A.O.; Jenner, M.C.; Moule, M.G.; Denman, C.; Cuccui, J.; Atkins, T.P.; Wren, B.W.; et al. An O-Antigen Glycoconjugate Vaccine Produced Using Protein Glycan Coupling Technology Is Protective in an Inhalational Rat Model of Tularemia. J. Immunol. Res. 2018, 2018, 1-12. [CrossRef]

31. Wacker, M.; Wang, L.; Kowarik, M.; Dowd, M.; Lipowsky, G.; Faridmoayer, A.; Shields, K.; Park, S.; Alaimo, C.; Kelley, K.A.; et al. Prevention of Staphylococcus aureus infections by glycoprotein vaccines synthesized in Escherichia coli. J. Infect. Dis. 2013, 209, 1551-1561. [CrossRef] [PubMed]

32. Herbert, J.; Kay, E.J.; Faustini, S.E.; Richter, A.; Abouelhadid, S.; Cuccui, J.; Wren, B.; Mitchell, T. Production and efficacy of a low-cost recombinant pneumococcal protein polysaccharide conjugate vaccine. Vaccine 2018, 36, 3809-3819. [CrossRef] [PubMed]

33. Reglinski, M.; Ercoli, G.; Plumptre, C.; Kay, E.; Petersen, F.C.; Paton, J.C.; Wren, B.W.; Brown, J.S. A recombinant conjugated pneumococcal vaccine that protects against murine infections with a similar efficacy to Prevnar-13. Vaccines 2018, 3, 53. [CrossRef]

34. Faridmoayer, A.; Fentabil, M.A.; Haurat, M.F.; Yi, W.; Woodward, R.; Wang, P.G.; Feldman, M.F. Extreme Substrate Promiscuity of the Neisseria Oligosaccharyl Transferase Involved in Protein O-Glycosylation. J. Boil. Chem. 2008, 283, 34596-34604. [CrossRef] [PubMed] 
35. Sun, P.; Pan, C.; Zeng, M.; Liu, B.; Liang, H.; Wang, D.; Liu, X.; Wang, B.; Lyu, Y.; Wu, J.; et al. Design and production of conjugate vaccines against S. Paratyphi A using an O-linked glycosylation system in vivo. Vaccines 2018, 3, 4. [CrossRef] [PubMed]

36. Harding, C.M.; Nasr, M.A.; Scott, N.E.; Goyette-Desjardins, G.; Nothaft, H.; Mayer, A.E.; Chavez, S.M.; Huynh, J.P.; Kinsella, R.L.; Szymanski, C.M.; et al. A platform for glycoengineering a polyvalent pneumococcal bioconjugate vaccine using E. coli as a host. Nat. Commun. 2019, 10, 891. [CrossRef] [PubMed]

37. Gu, W.; Wang, X.; Qiu, H.; Cui, B.; Zhao, S.; Zheng, H.; Xiao, Y.; Liang, J.; Duan, R.; Jing, H. Comparison of Cytokine Immune Responses to Brucella abortus and Yersinia enterocolitica Serotype O:9 Infections in BALB/c Mice. Infect. Immun. 2013, 81, 4392-4398. [CrossRef]

38. Pan, C.; Sun, P.; Liu, B.; Liang, H.; Peng, Z.; Dong, Y.; Wang, D.; Liu, X.; Wang, B.; Zeng, M.; et al. Biosynthesis of Conjugate Vaccines Using an O-Linked Glycosylation System. mBio 2016, 7, e00443-16. [CrossRef]

39. Baldauf, K.J.; Royal, J.M.; Hamorsky, K.T.; Matoba, N. Cholera Toxin B: One Subunit with Many Pharmaceutical Applications. Toxins 2015, 7, 974-996. [CrossRef]

40. Chen, L.; Valentine, J.L.; Huang, C.-J.; Endicott, C.E.; Moeller, T.; Rasmussen, J.A.; Fletcher, J.R.; Boll, J.M.; Rosenthal, J.A.; Dobruchowska, J.; et al. Outer membrane vesicles displaying engineered glycotopes elicit protective antibodies. Proc. Natl. Acad. Sci. USA 2016, 113, E3609-E3618. [CrossRef]

41. Sun, J.-B.; Czerkinsky, C.; Holmgren, J. Mucosally induced Immunological Tolerance, Regulatory T Cells and the Adjuvant Effect by Cholera Toxin B Subunit. Scand. J. Immunol. 2010, 71, 1-11. [CrossRef] [PubMed]

42. Brandao, A.P.; Oliveira, F.S.; Carvalho, N.B.; Vieira, L.Q.; Azevedo, V.; Macedo, G.C.; Oliveira, S.C. Host Susceptibility to Brucella Abortus Infection Is More Pronounced in Ifn-Gamma Knockout Than Il-12/Beta2-Microglobulin Double-Deficient Mice. Clin. Dev. Immunol. 2012, 2012, 589494. [CrossRef] [PubMed]

43. López-Santiago, R.; Sánchez-Argáez, A.B.; De Alba-Núñez, L.G.; Baltierra-Uribe, S.L.; Moreno-Lafont, M.C. Immune Response to Mucosal Brucella Infection. Front. Immunol. 2019, 10, 1759. [CrossRef] [PubMed]

(C) 2020 by the authors. Licensee MDPI, Basel, Switzerland. This article is an open access article distributed under the terms and conditions of the Creative Commons Attribution (CC BY) license (http://creativecommons.org/licenses/by/4.0/). 